INDEPENDENT JOURNAL OF MANAGEMENT \& PRODUCTION (IJM\&P)

http://www.ijmp.jor.br $\quad$ v. 11, n. 5, Special Edition IFLOG 2019 -September 2020 ISSN : 2236-269X

DOI: 10.14807/ijmp.v11i5.1286

\title{
DISCRETE EVENT SIMULATION FOR PROBLEM SOLVING IN THE CONTEXT OF AN EMERGENCY DEPARTMENT
}

Letícia Ali Figueiredo Ferreira CEFET/RJ, Brazil

E-mail: leticialifig@gmail.com

Igor Leão dos Santos

CEFET/RJ, Brazil

E-mail: igor.santos@cefet-rj.br

Ana Carla de Souza Gomes dos Santos IFRJ - Nilopolis and CEFET/RJ, Brazil

E-mail: anacarla.engenharia@gmail.com

Augusto da Cunha Reis

CEFET/RJ, Brazil

E-mail: augusto.reis@cefet-rj.br

Submission: $2 / 25 / 2020$

Accept: 2/29/2020

\section{ABSTRACT}

Emergency departments (ED) are responsible for the immediate care and stabilization of patients in critical health conditions. Several factors have caused overcrowding in the emergency care system, but the variability of patient arrival and the triage process requires special attention. The criticality of these components and their configuration directly impact the waiting times, length of stay and quality of service, being the subject of several studies. So, this paper aims to understand by means of Discrete Event Simulation how ED works with the variation of patient arrival and how this variation highlights the bottlenecks of the triage process. Varying the patient arriving interval between 0.1 and 7.6 in a 4-hour scenario, the system saturation point was established in $\beta=1.1$. Besides, with the variation in the number of triages points, a considerable decrease in the total length of stay spent and the waiting times were noticed, mainly when there was two triage points operating simultaneously.

Keywords: Emergency Department; Discrete Event Simulation; Brazil 
DOI: 10.14807/ijmp.v11i5.1286

\section{INTRODUCTION}

Emergency Departments (E.D.) are described as crucial elements of the healthcare system and one of the hospital's main entry points. However, these units are commonly perceived as a recurrent source of crisis in healthcare systems around the world and receives a great deal of attention in the literature (ZEINALI; MAHOOTCHI; SEPEHRI, 2015; YARMOHAMMADIAN et al., 2017; VANBRABANT et al., 2019). Countries such as the United States, Canada, Australia, the United Kingdom, and China have already been the target of studies regarding management challenges in their respective E.Ds. (DI SOMMA et al., 2015; MOHIUDDIN et al., 2017; WANG et al., 2018; CHENG et al., 2019).

Currently, Brazil is facing a scenario of consumption contraction, population aging, and increased migration, especially in large urban centers. This scenario has been directly reflecting in its emergency care departments, overloading its capacity (BARBOSA FILHO, 2017; TORTORELLA et al., 2017; YARMOHAMMADIAN et al., 2017; EMINE et al., 2018; VANBRABANT et al., 2019). Thus, Brazilian E.Ds managers are dealing with increasingly challenging aspects. According to data released by the Municipal Hospital Authority of São Paulo (2019), outpatient care in city public hospitals increased by $10 \%$ in 2018 . On the other hand, the Department of Hospital Management (DHM) stated that there was an increase of up to $44 \%$ in the number of emergency service care between 2017 and 2018 in the six federal hospitals located in Rio de Janeiro. Thus, despite challenges in E.Ds being a global issue, the current Brazilian healthcare scenario makes actions and efforts made in this area more urgent (EMINE et al., 2018; YARMOHAMMADIAN et al., 2017).

Moreover, this particular scenario is not only impacted, but also aggravated by issues related to overcrowding, queues, delays, and resource management issues that have long been affecting care services and, therefore, the whole E.D. (ZEINALI; MAHOOTCHI; SEPEHRI, 2015; GÖTTEMS et al., 2016; YARMOHAMMADIAN et al., 2017; YOUSEFI; FERREIRA, 2017; SALDIVA et al., 2018). Such problems are even more troubling when considering their negative effects on both the perceived quality of the services provided and the safety and quality of patient clinical care (WHITE et al., 2014; LEE et al., 2017).

Among several aspects of E.Ds, the variability of both patient arrival and triage process requires special attention (OLUGBOJI et al., 2018). The first identifies initial signs of adverse flows and is characterized by demand. On the other hand, the triage is perceived as a critical bottleneck since its management not only conducts the pace of attending and care throughout 
DOI: 10.14807/ijmp.v11i5.1286

the E.D but also directly influences its resource utilization and patient throughput TIME (ASPLIN et al., 2003; VAN DER LINDEN, MEESTER AND VAN DER LINDEN, 2016; LIU; HO, 2018; ARAZ; OLSON; RAMIREZ-NAFARRATE, 2019). Thus, these two aspects are the main actors in this study.

Despite their clear importance, there are other aspects that cannot be disregarded while analyzing patient arrival and triage processes. E.Ds are characterized precisely by the complexity of their services and operations and their multiple resources. So, implementing actions to improve E.Ds performance might be more complex than expected (ISMAIL; THORWARTH; ARISHA, 2014; WHITE et al., 2014; WILER et al., 2015; GÖTTEMS et al., 2016). Several computational resources, including Discrete Event Simulation (DES), are presented as solutions to determine and analyze improvement proposals in E.Ds before their actual implementation since these tools are flexible and can replicate several hospital configurations over time (LIN; KAO; HUANG, 2015; MOHIUDDIN et al., 2017; AHALT et al., 2018).

Based on the aforementioned information and considering the overcrowding problems in the emergency departments, this study aims to understand how E.D's services behave face patient arrival variation and how this variation highlights the bottleneck in the triage process by using DES.

To this end, this paper presents a brief literature review about E.Ds in section 2. Section 3 describes the methodology. Section 4 presents the results and analyzes, and finally, section 5 presents this work's final considerations.

\section{EMERGENCY DEPARTMENT (ED)}

By definition, emergency departments are healthcare sectors that provide care services by directing their resources to stabilize patients with acuity illness in need of emergency treatments. Due to the nature of the care offered, E.Ds operate on a spontaneous demand without the need for prior scheduling (MOHIUDDIN et al., 2017; WANG et al., 2018). Also, the standard operation of an ED is 24/7, uninterruptedly (MOHIUDDIN et al., 2017).

According to Asplin et al. (2003), the input-throughput-output conceptual model can be applied in patient flow operations management in emergency service care, especially when it comes to its overload analysis. The input elements of the conceptual model include any condition, event, or system that characterizes or contributes to an E.D's demand. The throughput components are mainly related to patient arrival, triage process, diagnosis, and 
DOI: 10.14807/ijmp.v11i5.1286

treatment. And finally, the output components concern aspects related to patients' admission and discharge after the provided care.

Although it is from 2003, the input-throughput-output model is still widely used, as observed in Lin, Kao, and Huang, (2015), Vashi et al. (2019) and Yarmohammadian et al. (2017). Figure 1 illustrates how it is its configuration.

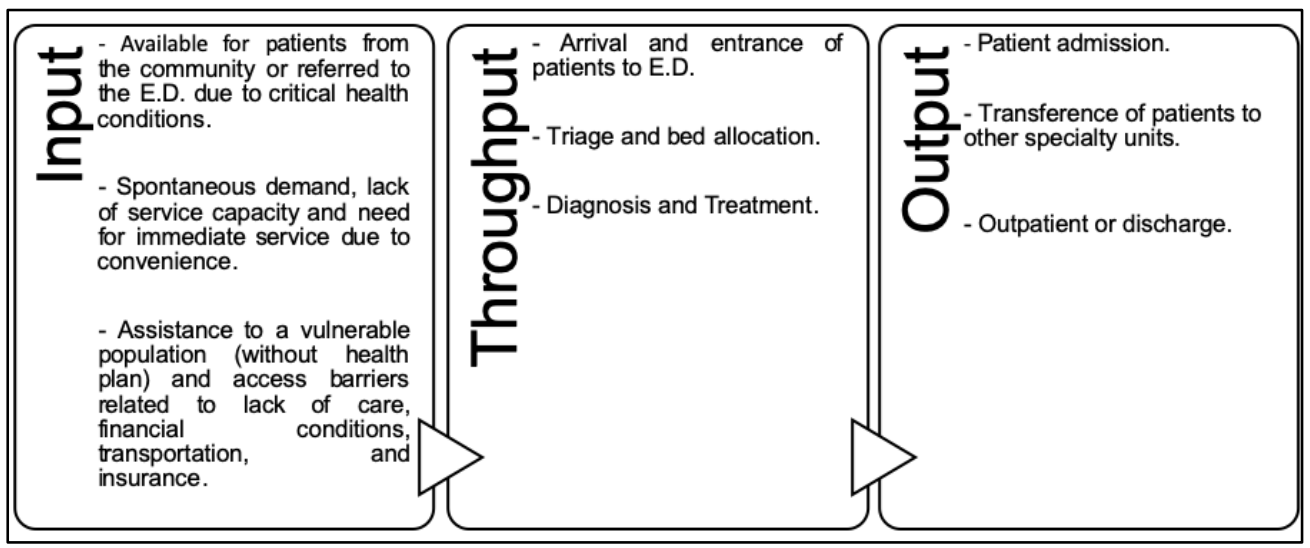

Figure 1: Conceptual input-throughput-output model for emergency service care

The throughput is a function of patient volume (input) and acuity, length of stay, and time required for patient admission, hospitalization or discharge (output) (MELTON et al., 2016). Comprehending the purpose of these components and their relationship with each other helps to understand the aspects that directly influence overload and overcrowding that affects E.D. (LIN; KAO; HUANG, 2015).

In the USA, lean concepts have been adapted to improve emergency service care throughput and patient satisfaction (KANE et al., 2015). In Melton et al. (2016), the rate of patients leaving ED without care decreased from $4 \%$ to $0.49 \%$ after efforts directed to aspects related to the throughput. In Australia and Canada, the increase in output resources has had more impacts on reducing patients' length of stay in emergency departments than efforts in input and throughput components (CHENG et al., 2019).

Thus, the search for improvements in emergency care processes is constant. Challenges can be addressed at various levels, from reducing patient flow and improving their work procedures to a holistic approach to total patient management (VON THIELE SCHWARZ; HASSON; MUNTLIN ATHLIN, 2016).

\section{METHODOLOGY}

The methodology is threefold. First, section 3.1 presents a scenario for emergency care characterized by numerical distributions and parameters as found in Marcelino, Lopes, and 
DOI: 10.14807/ijmp.v11i5.1286

Capocci (2015) and Sanches, Santos, and Silva (2016). Then, section 3.2 describes how a Discrete Event Simulation algorithm was developed to simulate the scenario described in 3.1. Finally, section 3.3 presented the simulation assumptions, as well as the main extracted metrics.

\subsection{E.D. scenario}

The scenario was based on a model consisting of a set of theoretical probability distributions that represent the patient's flow and the resources' attending time (secretaries, doctors, and nurses). Moreover, this model follows the operational input-throughput-output structure proposed in Asplin et al. (2003). As aforementioned, it also highlights the E.D processes that contribute substantially to its overcrowding, focusing on the throughput component, as illustrated in Figure 2.

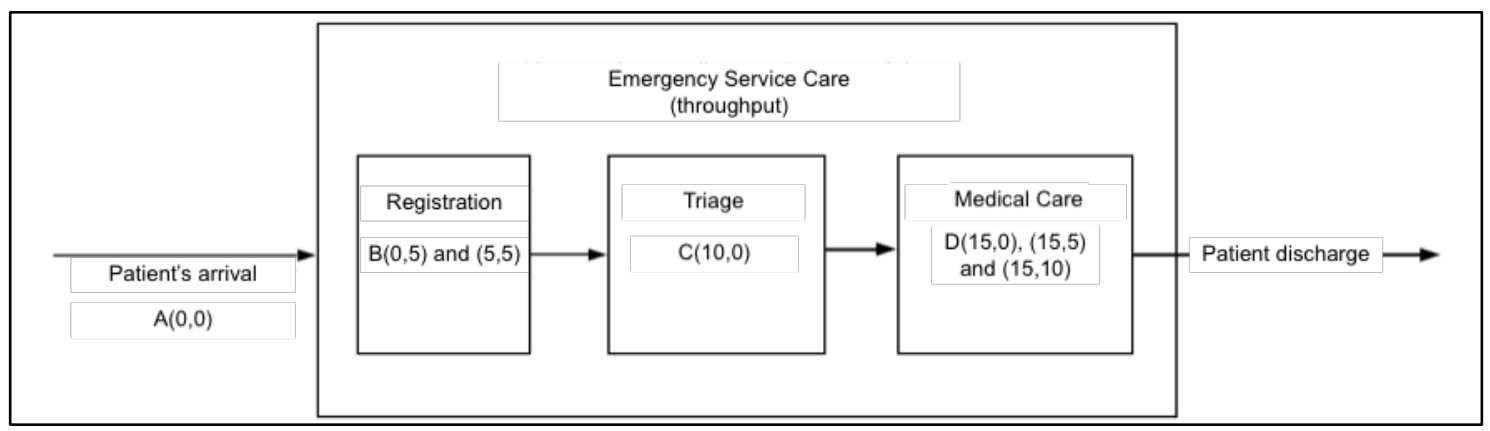

Figure 2: Throughput processes that contribute to E.D overloading

As this work focuses on the patient's throughput time in an emergency department, the aspects related to the input and output processes will not be considered. Thus, the E.D. simulated operates in an uninterrupted 4-hour shift through registration, triage, and medical care. Four hours is the amount of desirable time for a patient to remain in an E.D before being admitted, hospitalized, or discharged (VAN DER LINDEN; MEESTER; VAN DER LINDEN, 2016).

To determine a patient's location while he is going through any emergency department processes (registration - triage - medical care), a pairwise system where each pair (x,y) is attributed to the points A, B, C, and D present in the E.D conceptual model showed in Fig. 2 is used. The values of $\mathrm{x}$ and $\mathrm{y}$ are defined in meters (m). Each time the patient walks between these points, there is an increment to his Length of Stay (LOS). The LOS is defined as the amount of time a patient stayed in the E.D, that is, the time when the patient leaves the E.D minus the time when the patient arrives at the E.D.

The arrival interval between two patients (Figure 1, point A) is defined by an exponential distribution with an expected value of $\beta=1 / \lambda$, where $\lambda$ is the patient's arrival rate. 
DOI: 10.14807/ijmp.v11i5.1286

Initially, $\beta=7.5$. Upon arrival, the patient is at the $x, y=(0,0)$. Moreover, the interval time between consecutive patient arrivals $(\beta)$ has no variation throughout the day and it remains steady over time. Besides, how a patient arrives at the ED is irrelevant since this paper analyzes only what happens after arrival.

Upon arrival, patients go to the registration process (Figure 1, point B), where two secretaries are working. The secretaries working rate is described in this model in terms of a Weibull distribution with the following parameters: $\alpha=2.3847$ and $\delta=3.0524$. Moreover, this model also considers that there might be waiting between attendings due to short arrival intervals, so queues are expected. The secretaries' queues are managed by the first-in, first-out (FIFO) dynamic, meaning the first patient to enter the queue is the first patient to leave it to go to the next process (triage). The average time patients spent in a secretary's queue is defined by QTSec.

Secretaries 1 and 2 are located at points $\mathrm{x}, \mathrm{y}=(5,0)$ and $\mathrm{x}, \mathrm{y}=(5,5)$, respectively. So, the patient's path is defined by his dislocation from the ED entry point where $x, y=(0,0)$ to where the secretary with the shortest queue at the moment of his arrival is located. In case said secretary is attending at the moment the patient arrives at the ED, he waits in this secretary queue until he/she is available for the next patient.

After registering, patients are submitted to the triage process, which in this model consists of a randomized ordinal classification system (Figure 1, point C). In this system, numbers from 1 to 5 represent each of the priority levels, which extend from the most to the least degree of acuity. Therefore, we have that $1=$ Critical; $2=$ Very Urgent; $3=$ Urgent; 4 = Less Urgent and 5 = Non-Urgent. In this simulation, it was considered that the probability for a patient to be categorized into any priority level is the same for all levels. That is, there is the same chance that a patient will be classified as Non-Urgent or Critical during this process.

In this model, triage is managed by a Triangular distribution represented by TRIA $(2,3,4)$ and its attendance is carried out sequentially and uniquely. So, the resources addressed to this process is allocated to one patient at a time. When this patient is released to medical care, another one comes in. The triage process is located at $x, y=(10,0)$ and there is also the possibility of queues between the registration and triage processes. Triage queues are defined by $Q T_{T r i}$.

This simulation prioritizes high-acuity-patients to receive medical care, considering the following classification order: Critical, Very Urgent, Urgent, Less Urgent, Non-Urgent. Thus, 
DOI: 10.14807/ijmp.v11i5.1286

after triage, patients are ordered into the queues for medical care, and their position in the queue is defined by their priority level. When two or more patients are classified at the same priority level, their arrival time is considered. That is, if two patients are available for medical care at the same time, what defines who will be seen first by a doctor will be the priority level received during the triage stage. However, if the priority level is the same between these two patients, what defines the attendance order is the patient's arrival time at the E.D.

Finally, patients are referred to medical care (Figure 1, point D). Three doctors are considered in this scenario and are located at points $x, y=(15,0), x, y=(15,5)$ and $x, y=$ $(15,10)$, respectively. The doctor's operation time is defined by a Gamma distribution in which $\alpha=3.5956$ and $\beta_{\text {gamma }}=1.7646$. To calculate the patient's path, the simulation considers the distance from the triage point where he was classified $(x, y=(10,0))$ to an available doctor or the doctor with the shortest queue. In case said doctor is attending at the moment the patient leaves the triage process, the patient waits in the doctor's queue until this doctor is available for the next attending. The doctor's queue time is defined by $Q T_{\text {Med. }}$

Table 1 presents the processes, their main resources, their respective parameters, and distributions in the described scenario.

Table 1: Processes and their respective resources, distributions, and parameters

\begin{tabular}{|c|c|c|c|}
\hline Processes & Resources & Distributions & Essential Parameters \\
\hline Arrival & 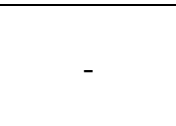 & Exponential & $\begin{array}{c}\beta=\text { expected value; interval time between } \\
\text { consecutive patient arrivals } \\
\lambda=\text { arrival rate }\end{array}$ \\
\hline Registration & Secretary & Weibull & $\begin{array}{c}\alpha=\text { scale parameter } \\
\text { e } \delta=\text { shape parameter }\end{array}$ \\
\hline Triage & Nurse & Triangular & $\begin{array}{c}\mathrm{a}=\text { lower limit, } \mathrm{b}=\text { mode and } \\
\mathrm{c}=\text { upper limit }\end{array}$ \\
\hline Medical Care & Doctor & Gamma & $\begin{array}{c}\alpha=\text { shape parameter and } \\
\boldsymbol{\beta}_{\text {gam } \boldsymbol{m} \boldsymbol{a}}=\text { scale parameter }\end{array}$ \\
\hline \multicolumn{4}{|l|}{ Other parameters } \\
\hline \multicolumn{4}{|c|}{$\begin{array}{l}\mathrm{T}=\text { simulation time }(\min )=4 \mathrm{~h} \\
\mathrm{~N}_{\text {sec }}=\text { number of available secretaries }=2 \\
\mathrm{~N}_{\text {tri }}=\text { number of triage points }=1 \\
\mathrm{~N}_{\text {med }}=\text { number of available doctors }=3\end{array}$} \\
\hline
\end{tabular}

\subsection{Discrete Event Simulation}

The simulation model described in Section 3.1 was written and implemented in Python. Each experimental scenario was simulated 10 times to obtain 95\% confidence. A notebook computer equipped with an Intel Core i5 processor and 4 GB of RAM was used to run the simulations. The data for each simulation was collected for analysis and graphing. The simulator, which follows the usual logic of the discrete event simulation, consists of the main 
DOI: 10.14807/ijmp.v11i5.1286

program, event initialization, clock, random number generator based on the distributions determined in the previous section, and several classes that represent the different processes and their resources (LIN; KAO; HUANG, 2015; MOHIUDDIN et al., 2017).

The main function controls the entire simulation flow by performing a loop while the simulation's conditions are not met. These conditions are: (i) if there are no more events in the event list, and (ii) if the clock reaches a value beyond the 4-hour simulation time, the simulation stops. Within the loop, the following operations are performed in that order: (i) move the clock to the next event, (ii) process events that occur at the current time, (iii) remove executed events from the list, (iv) move recent available patients (patients who have just gone through the registration, triage or medical care process), and (v) try to address resources to patients who are in queues.

Classes were implemented for each type of resource (classes "Secretary", "Triage", and "Doctor") and they all inherit the class "Resource". Also, there is a class that implements the characteristics of patients (class "Patient"). The events were also implemented from the classes, such as the patient's arrival at E.D. patient arrival at registration process, end of the registration process, the patient's arrival at triage process, end of the triage process, the arrival of the patient at medical care and end of medical care. All events inherit the generic class "Event" and have common methods to facilitate the management and performance of events in the event list. The performances of these events are chained together to simulate the entire patient's processing flow.

\subsection{Simulation's premises and metrics definition}

In this simulation, two experiments were performed and designed so that while one parameter (patient arrival interval and number of triage points) undergoes variations, the other parameters referring to other aspects of the scenario are kept constant. Thus, it is possible to understand how the system behaves in the face of proposed variations.

Based on the constructed scenario, Experiment 1 sought to determine at which point the emergency department begins to overload itself by defining a saturation point. This saturation point is defined by the expected value of interval time between consecutive patient arrivals ( $\beta$ ) in which there is an increase of patients in the triage queue.

Thus, in Experiment $1 N_{T r i}$ was kept constant and equal to 1 , and the parameter $\beta$ was varied to simulate different demand behaviors while the other variables also remained constant. The $\beta$ parameter assumed values between 0.1 and 7.6. Among these values, the maximum 
DOI: 10.14807/ijmp.v11i5.1286

saturation point of the E.D. system was determined. This saturation point is defined as $\beta_{\text {sat }}$ and is found when the average time spent in the triage process queue reaches its maximum value.

In Experiment 2, $\beta_{\text {sat }}$ was kept constant, while the number of triage points varied. Thus, $N_{\text {Tri }}$ assumed values between 1 and 4 and it was considered that, from that moment on, the emergency department could carry out up to 4 triages simultaneously in 4 sequential points located at $\mathrm{x}, \mathrm{y}=(10.0), \mathrm{x}, \mathrm{y}=(10.5), \mathrm{x}, \mathrm{y}=(10.10) \mathrm{ex}, \mathrm{y}=(10.15)$.

The values assigned for the simulation parameters for Experiments 1 and 2 are described in Table 2.

Table 2: Values assigned to the simulation parameters

\begin{tabular}{cc}
\hline Experiments & Valores recebidos \\
\hline \multirow{2}{*}{ Constants } & $\mathrm{T}=4(\mathrm{~h})$ or $240(\min ), \mathrm{N}_{\mathrm{sec}}=2$ e $\mathrm{N}_{\text {med }}=3$ \\
& Weibull $(\alpha=2,3847 \mathrm{e} \delta=3,0524)$ \\
Experiment 1 & $\mathrm{~N}_{\text {tri }}=1$ \\
& $\beta=[7,6 . .0,1]$ \\
Experiment 2 & $\mathrm{~N}_{\text {tri }}=[1,2,3,4]$ \\
& $\beta=\beta_{\text {sat }}$ \\
\hline
\end{tabular}

In addition to the values assigned to the parameters, some other premises must be considered for simulation purposes. Each time the patient moves between points A, B, C, and $\mathrm{D}$, there is an increase in their LOS. For this, the time spent to go from one point to another is defined in such a way that the $1 \mathrm{~m}$ displacement generates an increment of $1 \mathrm{~s}$ in the LOS. In this case, it is considered that the patient always moves in a straight line between two points.

At the end of the simulation, in addition to the average waiting queue time for each resource $\left(Q T_{T r i}, Q T_{S e c}\right.$, and $\left.Q T_{M e d}\right)$ and the patient's length of stay in the emergency department (LOS), the patient's total queue time $\left(Q T_{T o t}\right)$, and the patient's processing time $(P T)$ are determined. The $P T$ is defined by LOS minus $Q T_{T o t}$. From these data, analyses were carried out.

\section{RESULTS AND DISCUSSIONS}

The Experiment 1 sought to identify the saturation point of the emergency department care system through the variation of the time interval between consecutive patient arrivals $(\beta)$. Figure 3 demonstrates that the total number of patients in the hospital during the simulation time $\left(\mathrm{PN}_{\text {Total }}\right)$ increases when $\beta$ decreases. The number of patients attended $\mathrm{PN}_{\text {Atended }}=80$ remains constant, this being the value determined as the E.D's attending capacity during its 4hours operation. The other values showed in Figure 3 are the number of patients classified in each priority. Since it was assumed that there is an equal probability of occurrence among the 
DOI: 10.14807/ijmp.v11i5.1286

priority levels assigned to patients during the triage process, they are approximately the same values.

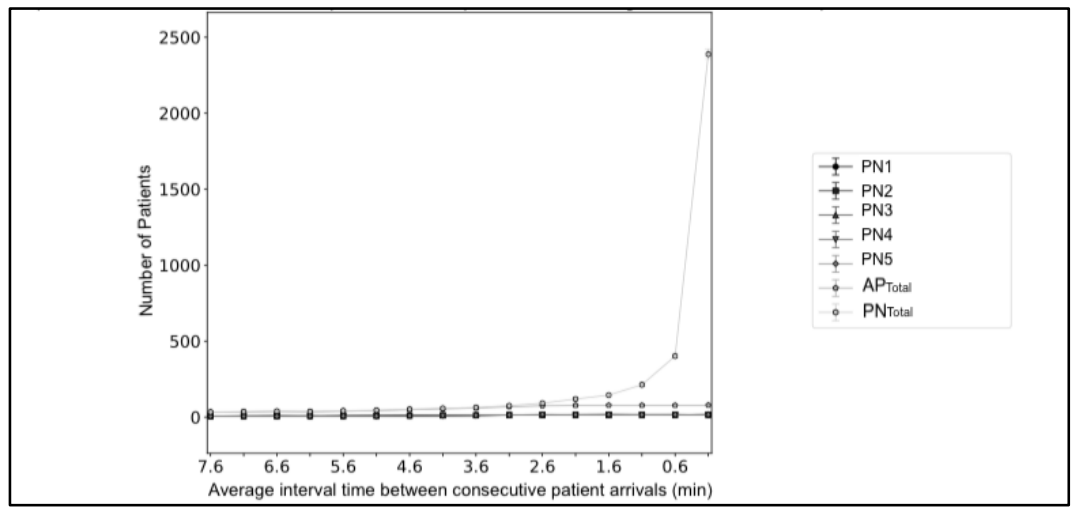

Figure 3: Total number of patients that arrived at the hospital, the total number of attended patients, and the number of patients classified in each priority during triage

The rate of patients attended to the total number of patients arriving at the E.D. (APTotal) decreases as $\beta$ decreases, and more patients are arriving at the emergency department. In Figure 4 , it is possible to notice a great decline in the $\mathrm{AP}_{\text {Total, meaning that even though patients are }}$ going through the registration process, the simulation time is ending before these patients get to the triage process. Meanwhile, the percentage of patients receiving proper medical care after the triage is close to $100 \%$, so all patients who have been gone through the triage are being attended by the doctors. These behaviors highlight the bottleneck in the triage since a large number of patients are being retained in this process. So, the retention of patients before they go through triage explains the decline of $\mathrm{AP}_{\text {Total. }}$.

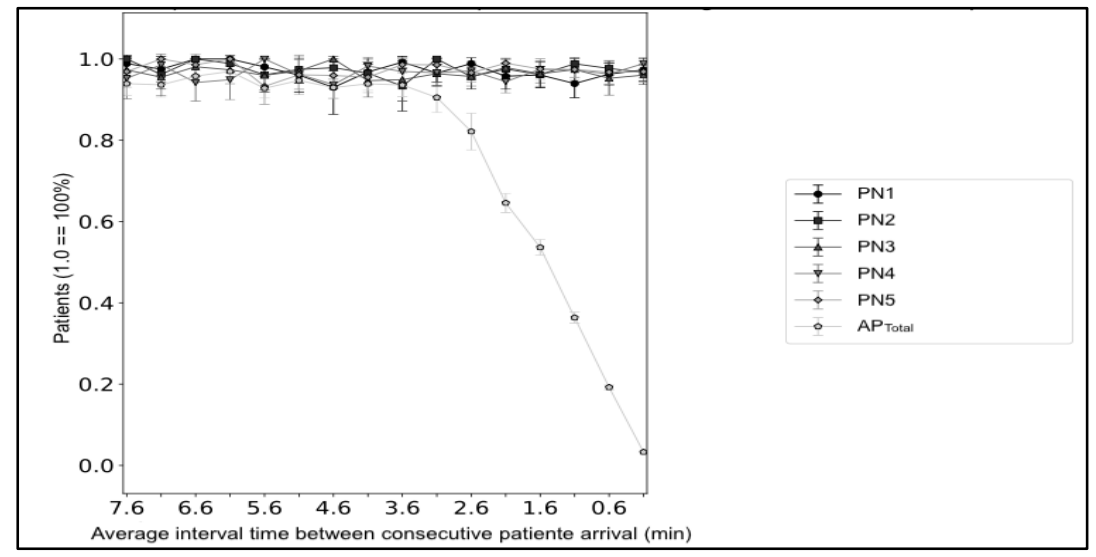

Figure 4: Rate of attending patients according to the expected time of patient arrivals

Figure 5 shows the average time of attending per resource (ATsec, ATTri, and ATMed) and the total attending time ( $\mathrm{AT}_{\mathrm{Tot}}$ ). It is important to note that these values are a direct result of the numerical distribution addressing each resource and tend to be constant with any parameter variation made. In this case, it keeps constant even after the variation of the time 
DOI: 10.14807/ijmp.v11i5.1286

between patient arrivals because these distributions demonstrate how long is each resource processing time.

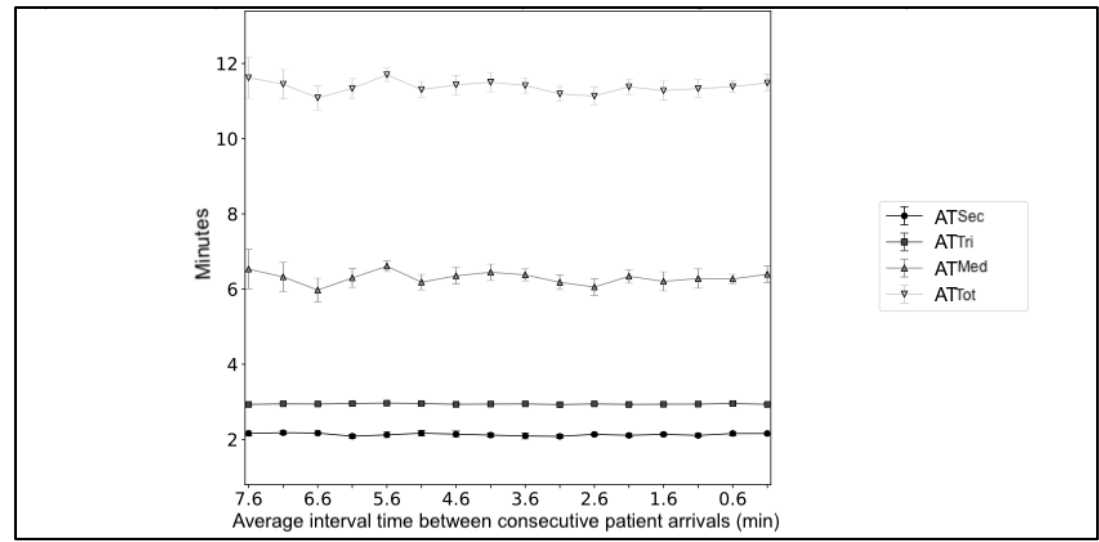

Figure 5: Total attending time and attending time per resource

Although resources operate at a constant pace, since they depend only on their respective numerical distribution, Figure 6 demonstrates that as there is a slight decline of $\beta$, the queue times of all resources increase. Thus, it is possible to see that with the increase in demand for emergency care, the system reaches an overload of its capacities. Again, it is possible to observe the bottleneck present in the triage process. Triage queue time (QTTri) has a great influence on the total queue time $\left(\mathrm{QT}_{\mathrm{Tot}}\right)$, once $\mathrm{QT}$ Tri is approximately equals to $\mathrm{QT}$ Tol.

It is also possible to observe that the secretariats only begin to have their capacities surpassed for $\beta$ values below 1.1 minutes. At the same time, QT Tri shows less growth and, soon after, becomes constant. Then, it is understood that at this point, the triage reached its maximum overload in the system, and the secretary resource is saturated, failing to direct more patients to this next process. As the retention is happening mainly in the triage stage, doctors do not have queues, and QT $\mathrm{Med}$ is almost zero.

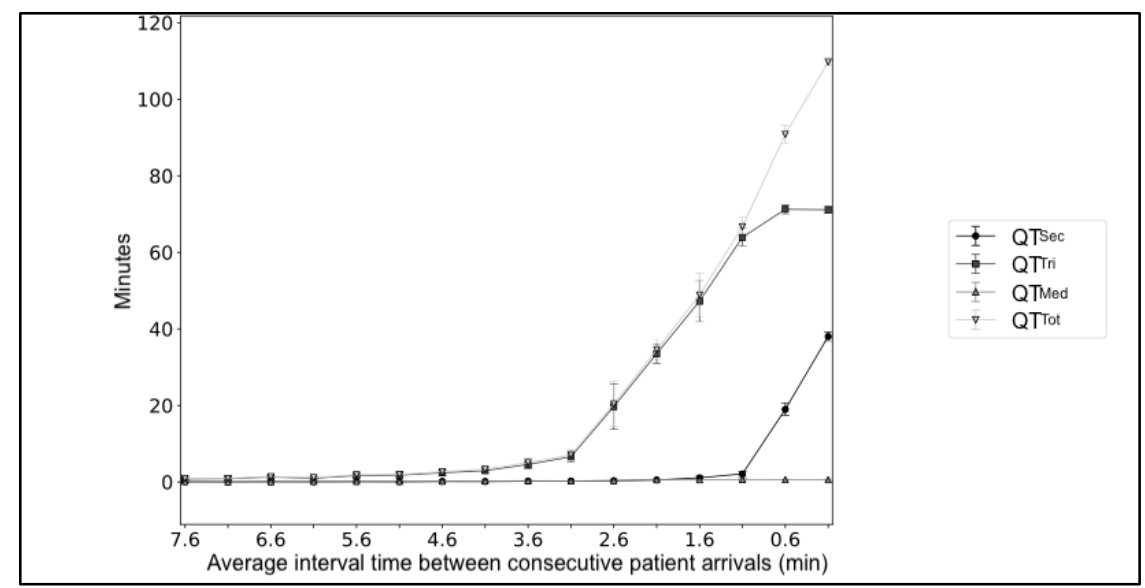

Figure 6: Total queue time and queue time per resource 
DOI: $10.14807 /$ ijmp.v11i5.1286

The average length of stay in the ED (LOS) increases as patients arrive more frequently, and the interval between patients arriving decreases (Figure 7). The processing time of the patient (PT), that is, the LOS minus the total queue time (QTTot), remains with a very low variation, being almost constant. When $\beta$ assumes values between $\beta=2.6$ minutes and $\beta=3.6$ minutes, it is clear that the difference between LOS and PT becomes even more evident. This is due to the increase in the total queue time, as previously shown since it is in this same range of $\beta$ values that QTTot presented a greater inclination in Figure 6.

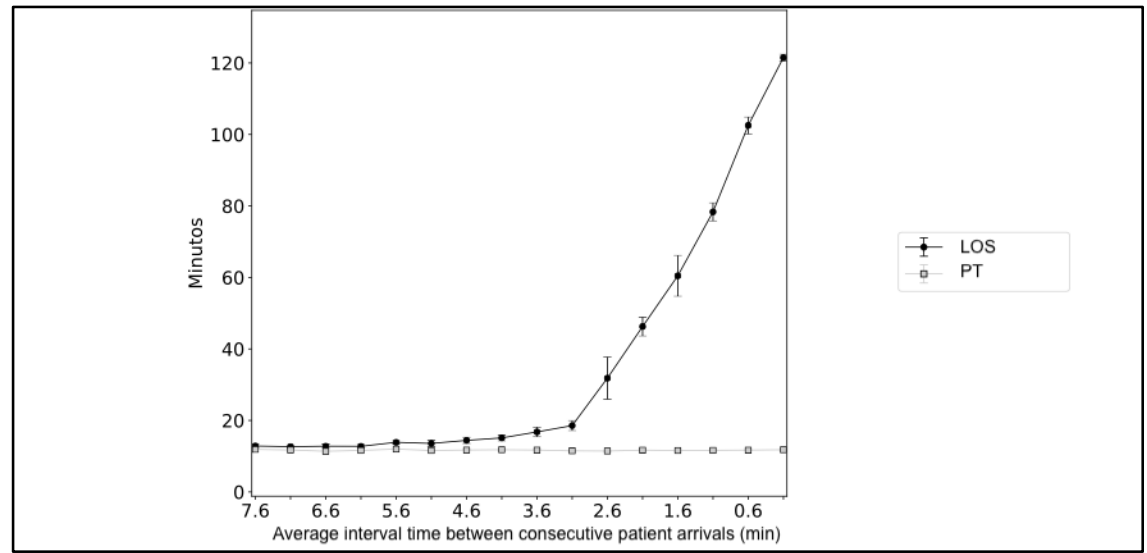

Figure 7: Length of Stay and Processing time

Analyzing the data obtained in Experiment 1, the maximum saturation point was $\beta_{\text {sat }}=$

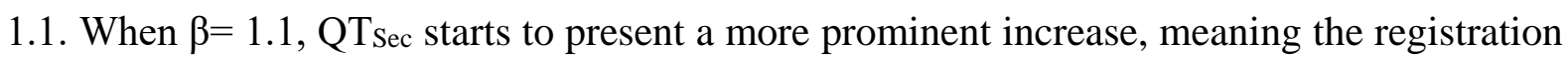
process saturated. So, that is the point when $\beta_{\text {sat }}=\beta$. In Figure 3, this increase is characterized by an abrupter inclination of $\mathrm{PN}_{\text {Total. }}$. At this point, the secretaries are directing patients to the triage, even though this process is already at its maximum capacity. This inclination is corroborated by Figure 6 , as $\beta_{\text {sat }}=1.1$ is the overload point of the triage process.

In Experiment 2, $\beta=1.1$ minutes, meaning the triage process is being demanded to the maximum. So, with a constant value for $\beta$ established, the number of triage points varied.

Figure 8 illustrates that increasing the number of triage points, more patients begin to have priority levels assigned, that is, more patients go through the triage process. Priority level 1 (Emergency) has the highest rate of care per doctor, while priority 5 patients (No Urgency) have the lowest rate of care per doctor. Since level 5 patients are always positioned at the end of the queue, this system behavior is expected, demonstrating that more emergency patients are being prioritized in the simulation. The percentage of attended patients ( $\mathrm{AP}_{\text {Total }}$ ) shows that a greater number of triages favor more patients receive care, with a greater accentuation of the AP Total between $\mathrm{N}_{\text {tri }}=1$ and $\mathrm{N}_{\text {tri }}=2$. When $\mathrm{N}_{\text {tri }}>2$, AP $\mathrm{A}_{\text {Total }}$ presents only a slight increase. 
DOI: 10.14807/ijmp.v11i5.1286

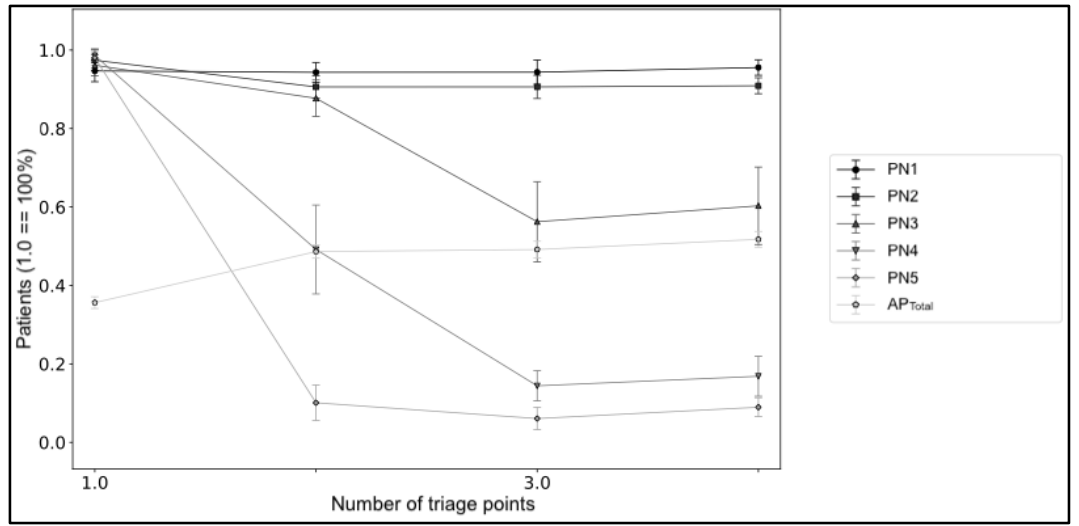

Figure 8: Percentage of attended patients when NTri assume different values

The total queue time (QTTot) decreased as the number of triage points, and so, the capacity to attend to the system bottleneck, increase (Figure 9). The QT sec has minimal variations since the change in the number of triage points occurs after the registration process is completed. When $\mathrm{N}_{T r i}=2$, there is a clear decrease in $\mathrm{QT}_{\text {Tri, }}$ which is the major determinant of the decrease in $\mathrm{QT}_{\mathrm{Tot}}$. Also, there is a more noticeable increase in $\mathrm{QT}_{\mathrm{Med}}$, meaning that more patients are being conducted to medical care, and the triage process is no longer a bottleneck.

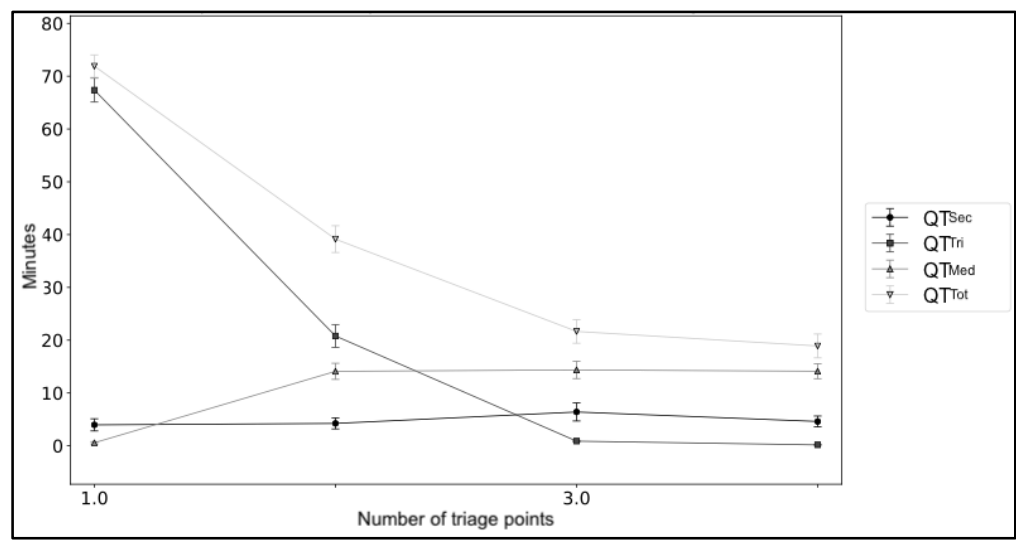

Figure 9: Total queue time and resources queue time when NTri assume different values

Figure 10 represents how the average length of stay (LOS) decreases as the number of triage points increase. The higher decrease occurs at $\mathrm{N}_{T r i}=2$, as the patient's stay time in the E.D. decreases from 80 to 50 minutes. When $\mathrm{N}_{\text {Tri }}=3$ and $\mathrm{N}_{\text {Tri }}=4$, the patient's stay time presents a smaller variation. 
DOI: 10.14807/ijmp.v11i5.1286

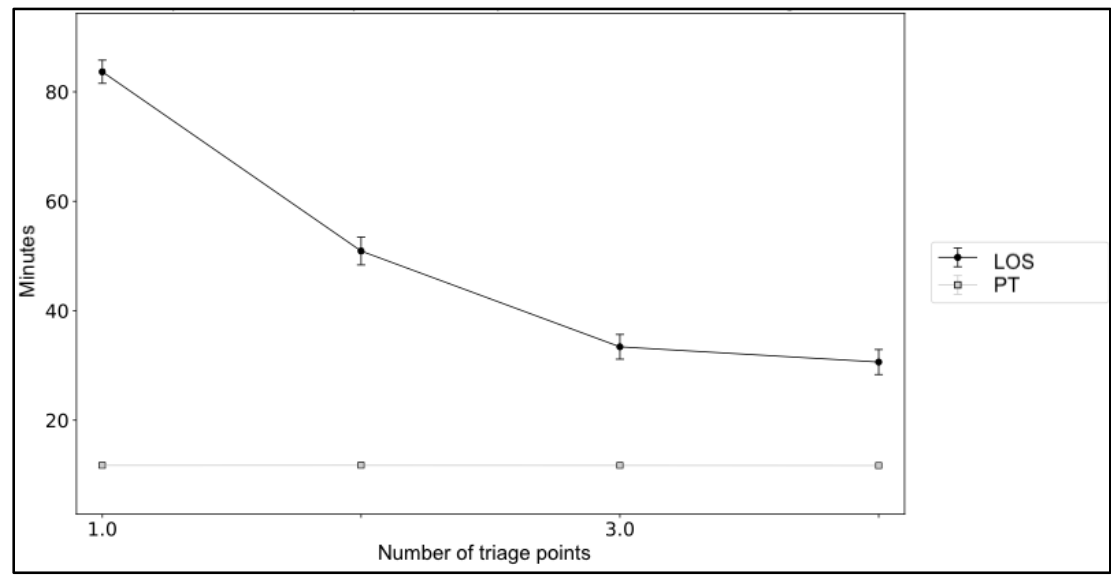

Figure 10: Length of Stay and Processing time when NTri assume different values

\section{CONCLUSIONS}

Emergency departments are crucial components of healthcare systems around the world and constantly face problems related to overcrowding and long queues. Its overload is defined by aspects that permeate its inputs, throughputs, and outputs.

This works focuses on throughput processes by seeking to understand how the variation in the arrival ratee highlights the bottlenecks of the triage process. Thus, when finding the saturation point of the system at $\beta$ sat $=1.1$ minutes, a substantial increase in both the secretary and triage queue time was observed, while medical queue time had small variations. It highlights the triage process as a bottleneck once it retains a large number of patients.

By varying the number of simultaneous triages performed, with the increase of triage points in the system, there was an improvement in the flow of patients throughout the E.D., with a decrease of up to 30 minutes in the total queue time and the length of stay. However, while two triage points allowed a greater reduction in these times, a total of 3 and 4 triage points showed a lesser reduction (about 20min and 5min, respectively). This might mean that there is an optimum number of triage points that provide a balance between decreasing the length of stay and the optimum use of resources.

For future work, it is recommended to perform a simulation in a more complex scenario, taking into account the relationships between the input-throughput-output components. It is also recommended to find the optimal number of triage points that reduce the time spent in the process and the queue time for resources, taking into account the utilization rate and the costs inherent to the resources (secretary, nurse, and doctors).

\section{ACKNOWLEDGEMENTS}


INDEPENDENT JOURNAL OF MANAGEMENT \& PRODUCTION (IJM\&P)

http://www.ijmp.jor.br

v. 11, n. 5, Special Edition IFLOG 2019 - September 2020

ISSN: 2236-269X

DOI: 10.14807/ijmp.v11i5.1286

The authors would like to thank CAPES for the scholarship provided to one of the authors of this work, and for supporting the development of Brazilian scientific research.

\section{REFERENCES}

AHALT, V.; ARGON, N. T.; ZIYA, S.; STRICKLER, J.; MEHROTRA, A. (2018)

Comparison of emergency department crowding scores: a discrete-event simulation approach, Health Care Management Science, v. 21, n. 1, p. 144-155. doi: 10.1007/s10729-016-9385$\mathrm{z}$.

ARAZ, O. M.; OLSON, D.; RAMIREZ-NAFARRATE, A. (2019) Predictive analytics for hospital admissions from the emergency department using triage information, International Journal of Production Economics, v. 208, p. 199-207. doi: 10.1016/j.ijpe.2018.11.024.

ASPLIN, B. R.; MAGID, D. J.; RHODES, K. V.; SOLBERG, L. I.; LURIE, N.; CAMARGO JUNIOR, C. A. (2003) A conceptual model of emergency department crowding, Annals of Emergency Medicine, v. 42, n. 2, p. 173-180. doi: 10.1067/mem.2003.302.

BARBOSA FILHO, F. H. (2017) A crise econômica de 2014/2017, Estudos Avançados, v. 31, n. 89, p. 51-60. doi: 10.1590/s0103-40142017.31890006.

CHENG, I.; TAYLOR, D.; SCHULL, M. J.; ZWARENSTEIN, M.; KISS, A.; CASTREN, M.; BROMMELS, M.; YEOH, M.; KERR, F. (2019) Comparison of emergency department time performance between a Canadian and an Australian academic tertiary hospital, Emergency Medicine Australasia, v. 31, n. 4, p. 605-611. doi: 10.1111/1742-6723.13247.

DI SOMMA, S.; PALADINO, L.; VAUGHAN, L.; LALLE, I.; MAGRINI, L.; MAGNANTI, M. (2015) Overcrowding in emergency department: an international issue, Internal and Emergency Medicine, v. 10, n. 2, p. 171-175. doi: 10.1007/s11739-014-1154-8.

EMINE, S.; BOULEUX, G.; HAOUBA, H.; MARCON, E. (2018) Emergency Department Overcrowding Detection by a Multifractal Analysis, in 10th IFAC Symposium on Biological and Medical Systems (IFACBMS 2018). Sao Paulo, Brazil. Available at: https://hal.archives-ouvertes.fr/hal-01876444 (Accessed: 2 September 2019), doi: 10.1016/j.ifacol.2018.11.659.

GÖTTEMS, L. B. D.; BITTENCOURT, R. J.; SANTANA, M. I. R. L.; PIRES, M. R. G. M.; CAMPO, J. (2016) Contratualização regionalizada de serviços públicos de saúde no Distrito Federal: relato de experiência, Revista Eletrônica Gestão e Saúde, n. 1, p. 282-308.

ISMAIL, K.; THORWARTH, M.; ARISHA, A. (2014) Integrated decision support systems for improving emergency department performance in irish hospitals, International Journal of Operational Research, v. 19, n. 1, p. 40-59. doi: 10.1504/IJOR.2014.057843.

KANE, M.; CHUI, K.; RIMICCI, J.; CALLAGY, P.; HEREFORD, J.; SHEN, S.; NORRIS, R.; PICKHAM, D. (2015) Lean Manufacturing Improves Emergency Department Throughput and Patient Satisfaction, JONA: The Journal of Nursing Administration, v. 45, n. 9, p. 429-434. doi: 10.1097/NNA.0000000000000228.

LEE, I.-H.; CHEN, C. T.; LEE, Y. T.; HSU, Y. S.; LU, C. L.; HUANG, H. H.; HSU, T. F.; HOW, C. K.; YEN, D. H.; YANG, U. C. (2017) A new strategy for emergency department crowding: High-turnover utility bed intervention, Journal of the Chinese Medical Association, v. 80, n. 5, p. 297-302. doi: 10.1016/j.jcma.2016.11.002.

LIN, C.-H.; KAO, C.-Y.; HUANG, C.-Y. (2015) Managing emergency department overcrowding via ambulance diversion: A discrete event simulation model, Journal of the 
INDEPENDENT JOURNAL OF MANAGEMENT \& PRODUCTION (IJM\&P)

http://www.ijmp.jor.br

v. 11, n. 5, Special Edition IFLOG 2019 - September 2020

ISSN: $2236-269 X$

DOI: 10.14807/ijmp.v11i5.1286

Formosan Medical Association, v. 114, n. 1, p. 64-71. doi: 10.1016/j.jfma.2012.09.007.

VAN DER LINDEN, M. C.; MEESTER, B. E. A. M.; VAN DER LINDEN, N. (2016)

Emergency department crowding affects triage processes, International Emergency

Nursing, v. 29, p. 27-31. doi: 10.1016/j.ienj.2016.02.003.

LIU, Y.-C.; HO, C. H. (2018) A comparison of car following behaviors: Effectiveness of applying statistical quality control charts to design in-vehicle forward collision warning systems, Transportation Research Part F: Traffic Psychology and Behaviour, v. 53, p. 143-154. doi: 10.1016/j.trf.2017.09.010.

MARCELINO, D. M.; LOPES, P. H.; CAPOCCI, N. R. (2015) Simulação: um estudo de caso de um hospital municipal no estado de São Paulo, São Paulo, p. 12.

MELTON, J. D.; BLIND, F.; HALL, A. B.; LECKIE, M.; NOVOTNY, A. (2016) Impact of a Hospitalwide Quality Improvement Initiative on Emergency Department Throughput and Crowding Measures, The Joint Commission Journal on Quality and Patient Safety, v. 42, n. 12, p. 533-542. doi: 10.1016/S1553-7250(16)30104-0.

MOHIUDDIN, S.; BUSBY, J.; SAVOVIC, J.; RICHARDS, A.; NORTHSTONE, K.; HOLLINGWORTH, W.; DONOVAN, J. L.; VASILAKIS, C. (2017) Patient flow within UK emergency departments: a systematic review of the use of computer simulation modelling methods, BMJ Open, v. 7, n. 5, p. e015007. doi: 10.1136/bmjopen-2016-015007.

OLUGBOJI, O.; CAMORLINGA, S. G.; FARIA, R. L.; KAUSHAL, A. (2018) Understanding the Emergency Department Ecosystem Using Agent-Based Modeling: A Study of the Seven Oaks General Hospital Emergency Department, in Sturmberg, J. P. (ed.) Putting Systems and Complexity Sciences Into Practice. Cham: Springer International Publishing, p. 199-214. doi: 10.1007/978-3-319-73636-5_15.

SALDIVA, P. H. N.; VERAS, M. (2018) Gastos públicos com saúde: breve histórico, situação atual e perspectivas futuras, Estudos Avançados, v. 32, n. 92, p. 47-61. doi: 10.5935/0103-4014.20180005.

SANCHES, C. B.; SANTOS, L. C.; SILVA, M. M. (2016) Modelagem e simulação do fluxo de pacientes em uma clínica médica, Revista GEINTEC - Gestão, Inovação e Tecnologias, v. 6, n. 2, p. 3079-3094. doi: 10.7198/geintec.v6i2.834.

VON THIELE SCHWARZ, U., HASSON, H. AND MUNTLIN ATHLIN, Å. (2016) 'Efficiency in the emergency department - A complex relationship between throughput rates and staff perceptions', International Emergency Nursing, 29, pp. 15-20. doi: 10.1016/j.ienj.2016.07.003.

TORTORELLA, G. L.; FOGLIATTO, F. S.; ANZANELLO, M.; MARODIN, G. A.; GARCIA, M.; ESTEVES, R. R. (2017) Making the value flow: application of value stream mapping in a Brazilian public healthcare organisation, Total Quality Management \& Business Excellence, v. 28, n. 13-14, p. 1544-1558. doi: 10.1080/14783363.2016.1150778.

VANBRABANT, L.; BRAEKERS, K.; RAMAEKERS, K.; NIEUWENHUYSE, I. A. (2019) Simulation of emergency department operations: A comprehensive review of KPIs and operational improvements, Computers and Industrial Engineering, v. 131, p. 356-381. doi: 10.1016/j.cie.2019.03.025.

VASHI, A. A.; SHEIKHI, F. H.; NASHTON, L. A.; ELLMAN, J.; RAJAGOPAL, P.; ASCH, S. M. (2019) Applying Lean Principles to Reduce Wait Times in a VA Emergency Department, Military Medicine, v. 184, n. 1-2, p. e169-e178. doi: 10.1093/milmed/usy165. 
WANG, Z.; XIONG, X.; WUANG, S.; YAN, J.; SPRINGER, M.; DELLINGER, R. P. (2018) Causes of Emergency Department Overcrowding and Blockage of Access to Critical Services in Beijing: A 2-Year Study, The Journal of Emergency Medicine, v. 54, n. 5, p. 665-673. doi: 10.1016/j.jemermed.2018.02.009.

WHITE, B. A.; CHANG, Y.; GRABOWSKI, B. G.; BROWN, D. F. M. (2014) Using leanbased systems engineering to increase capacity in the emergency department, Western Journal of Emergency Medicine, v. 15, n. 7, p. 770-776. doi:

10.5811/westjem.2014.8.21272.

WILER, J. L.; WELCH, S.; PINES, J.; SCHUUR, J.; JOURILES, N.; STONE-GRIFFITH, S. (2015) Emergency department performance measures updates: Proceedings of the 2014 emergency department benchmarking alliance consensus summit, Academic Emergency Medicine, v. 22, n. 5, p. 542-553. doi: 10.1111/acem.12654.

YARMOHAMMADIAN, M. H.; REZAEI, F.; HAGHSHENAS, A.; TAVAKOLI, N. (2017) Overcrowding in emergency departments: A review of strategies to decrease future challenges, Journal of Research in Medical Sciences : The Official Journal of Isfahan University of Medical Sciences, v. 22. doi: 10.4103/1735-1995.200277.

YOUSEFI, M.; FERREIRA, R. P. M. (2017) An agent-based simulation combined with group decision-making technique for improving the performance of an emergency department, Brazilian Journal of Medical and Biological Research, v. 50, n. 5. doi: 10.1590/1414-431X20175955.

ZEINALI, F.; MAHOOTCHI, M.; SEPEHRI, M. M. (2015) Resource planning in the emergency departments: A simulation-based metamodeling approach, Simulation Modelling Practice and Theory, v. 53, p. 123-138. doi: 10.1016/j.simpat.2015.02.002. 